\title{
Vascular malformation of the upper lip
}

\begin{abstract}
The term hemangioma has traditionally been applied to a variety of vascular lesions, ranging from lifelong conditions to self-limited, benign tumours of infancy. However, despite the frequency of these tumours, their pathogenesis is often incompletely understood and so the management of these lesions still remains controversial. Advances in imaging techniques and novel therapeutic approaches, have altered our understanding of this common problem and the way we approach it. We present a case of vascular malformation of the upper lip and labial mucosa that was surgically treated at our centre. Intraoral mucosal flap were advanced for primary closure of the defect. Postoperative phase was uneventful, six month follow up shows no recurrence of the lesion.
\end{abstract}

Keywords: vascular; malformation, upper lip, benign tumours, vascular lesions, intraoral mucosal flap; superior labial vessels, vascular anomalies, angiogenesis, lip mucosa, arterial, venous, lymphatic, congenital hemangioma, angiography
Volume 3 Issue 2 - 2015

Surej Kumar LK,' Manesh Senan, ${ }^{2}$ Varun

Menon P, Mathew PVarghese ${ }^{3}$

'Department of Oral \& Maxillofacial surgery, Kerala Institute of medical sciences, India

${ }^{2}$ Department of Plastic surgery, Kerala Institute of medical sciences, India

${ }^{3}$ Oral \& Maxillofacial Trainee, Kerala Institute of medical sciences, India

Correspondence: Varun Menon P, Oral \& Maxillofacial Trainee, Kerala Institute of medical sciences (KIMS), Trivandrum 695029, Kerala, India, Tel +918891787360,

Email varunmp@gmail.com

Received: August 10, 2015 | Published: November 05, 2015

\section{Introduction}

The term hemangioma has traditionally been applied to a variety of vascular lesions, ranging from lifelong conditions to self-limited, benign tumours of infancy. However, despite the frequency of these tumours, their pathogenesis is often incompletely understood and so the management of these lesions still remains controversial. This is predominantly due to an unclear understanding of the natural history of these lesions. Clinicians from many specialities are often involved in the diagnosis and management of these patients which have made them to search for solutions within their speciality and apply them to all lesions. It is therefore not surprising that, the lack of consensus on terminology, features and especially treatment of vascular anomalies has resulted in an outburst of literature that in many times, confusing.

Recent research on angiogenesis and pathophysiology, has improved the classification of vascular anomalies. Advances in imaging techniques and novel therapeutic approaches, have altered our understanding of this common problem and the way we approach it. We present a case of vascular malformation of the upper lip and labial mucosa that was surgically treated at our centre.

\section{Case report}

A 34year female patient reported to our department with complaints of recurrent swelling and mild discoloration of skin and upper lip mucosa. The discoloration was noticed for the past lyear and was not associated with pain. On clinical examination, extraorally mild swelling and discoloration of upper lip and skin was seen (Figure 1). The discoloration was also present on left inner side of mucosa of upper lip measuring around $2 \mathrm{cmX} 1.5 \mathrm{~cm}$, extending from mucogingival junction upto vermillion border. Mild pulsations were felt on palpation and angiogram was done. Superior labial vessels were identified as the source of vascular supply and no other collaterals were present. Wide excision of the lesion was planned under GA (Figure 3). Superficial mucosa and muscular layer were excised along with the lesion by locally ligating the superior labial vessels (Figure 4-6). Intraoral mucosal flap were advanced for primary closure of the defect (Figure 7). Postoperative phase was uneventful, six month follow up shows no recurrence of the lesion (Figure 8).

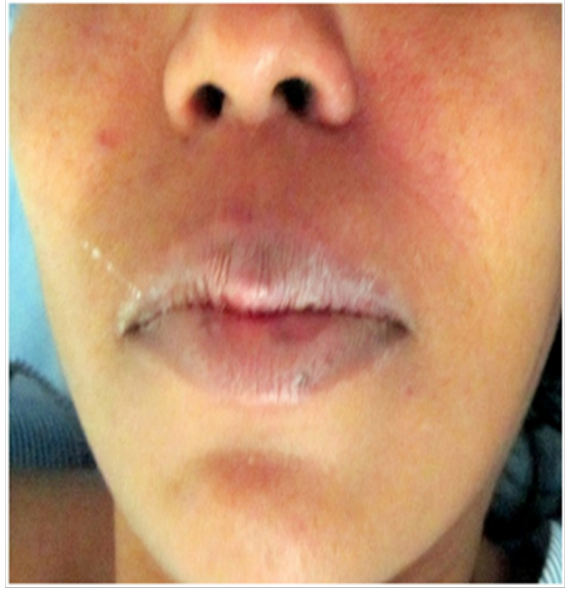

Figure I Extraoral clinical picture.

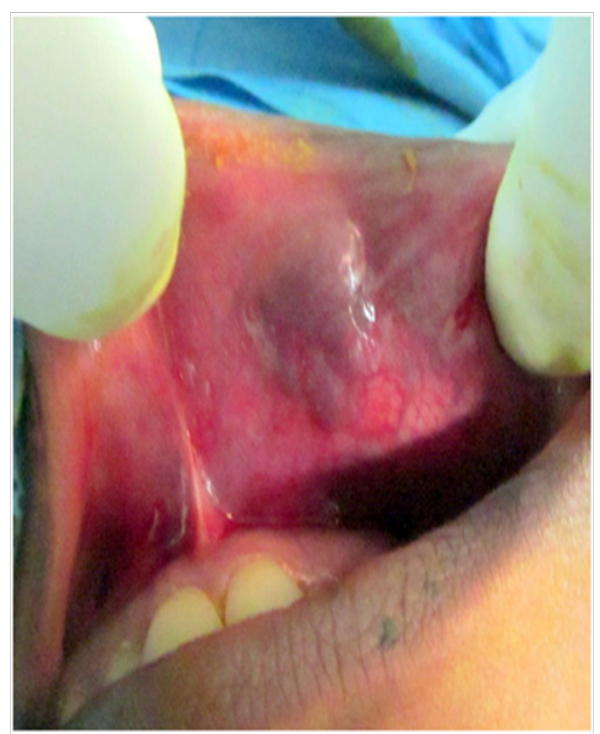

Figure 2 Intraoral clinical picture. 


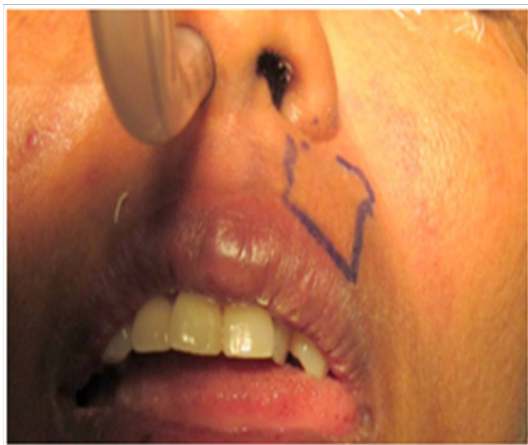

Figure 3 Skin marking for wide excision.

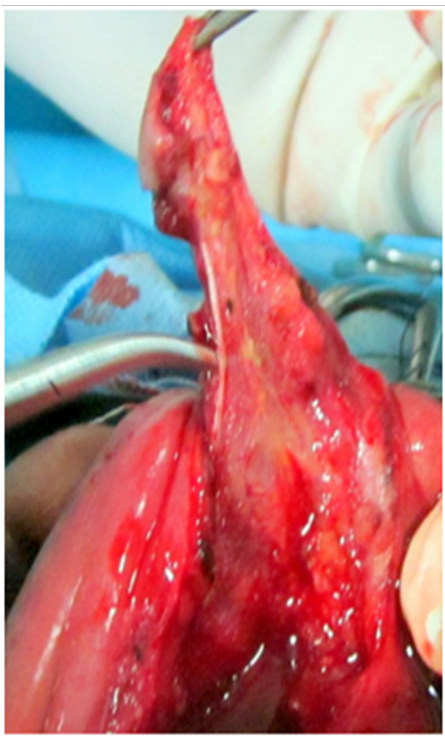

Figure 4 Ligation of the vessel and excision of the lesion.

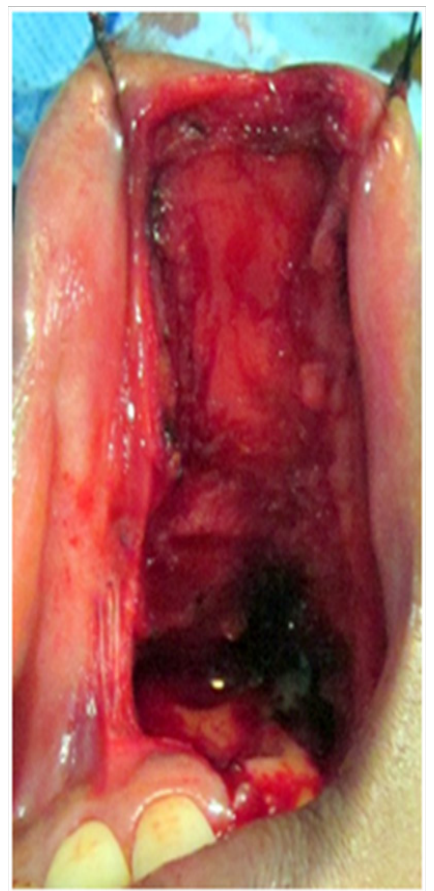

Figure 5 Surgical defect after excising the lesion.

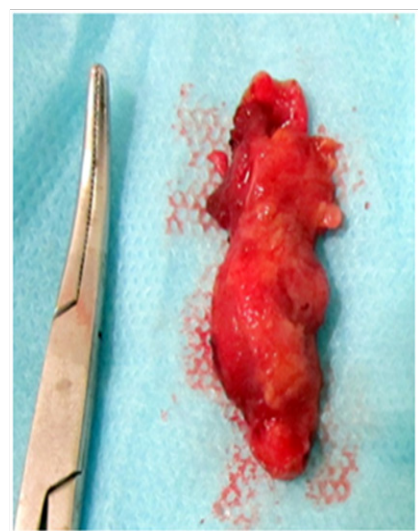

Figure 6 Excised lesion

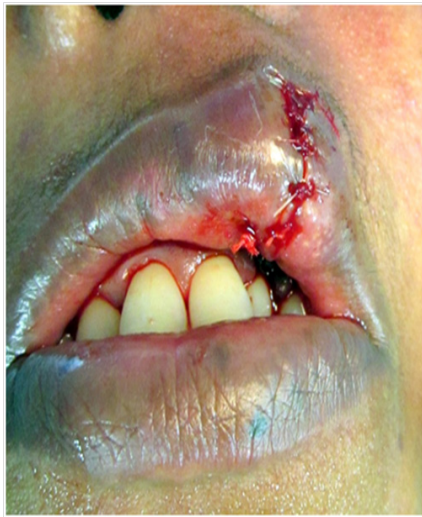

Figure 7 Primary closure of the defect with intraoral mucosal advancement flap.
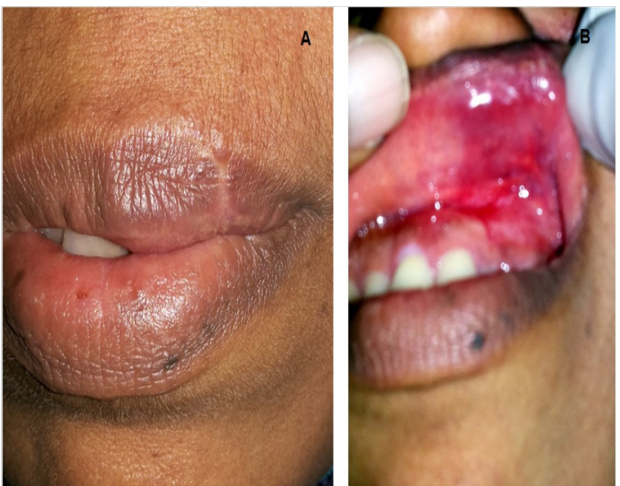

Figure 8 Follow up post operative picture

\section{Discussion}

Vascular anomalies are a group of lesions derived from blood vessels and lymphatics with widely varying histology and clinical behaviour. They constitute the most common congenital abnormalities in infants and children. The first public demonstration of ether anaesthesia by William Green Morton in 1846 was performed for surgical removal of a venous vascular malformation. ${ }^{1}$ Numerous attempts made over the years to understand, classify and treat these lesions, have generally met with unpredictable outcomes. James wardrop, a London surgeon, first recognized the differences between true hemangiomas and the less common vascular malformations in $1818 .^{2}$ In 1982, Mulliken et al., ${ }^{2}$ put forward a biologic classification of vascular birthmarks on 
the basis of their clinical manifestations, histopathological features and natural history. Subsequently, Mulliken et al., ${ }^{3}$ studies the flow dynamics of vascular lesions and described hi -flow and low-flow vascular malformations. In 1996 International Society for the study of Vascular Anomalies (ISSVA) added the rapidly involuting congenital hemangioma, noninvoluting congenital hemangioma, Kaposiform hemagioendothelioma, tufted angioma and pyogenic granuloma to the list of vascular tumours. ${ }^{4}$

The subsequent modification in classification by Waner et al., ${ }^{5}$ in 1999 is more practical and easily used clinically, in which hemangiomas are subdivided according to the predominant channel anomaly into either venular (capillary), arterial, venous, lymphatic. The classification by Ethunandan et al., ${ }^{6}$ has helped to consolidate many previous classifications. The authors have categorized vascular lesions requiring surgery into five types. This simplified categorization provides input into the investigation and effective surgical management of various lesions based on anatomical presentation.

The term vascular anomaly encompasses two distinct and diverse group of pathologies categorized as vascular tumors and vascular malformations in the classification of the International Society for the study of Vascular Anomalies. Vascular tumors are true neoplasms with pathologic cell proliferation, whereas vascular malformations are structural aberrations in components of the vascular apparatus with no abnormal cell turnover rate. Of hemangiomas occurring in childhood, 70 percent undergo spontaneous regression by the seventh year of life. ${ }^{3}$ Unless there is an overwhelming reason, psychological or otherwise for surgical or intervention, small haemangiomas are merely kept under observation.

Imaging is used to confirm the suspected diagnosis, establish the extent of the lesion and document any associated abnormalities. ${ }^{7}$ Magnetic resonance imaging is the investigation of choice as it provides accurate information about the extent of the lesion, better contrast between the different types of vascular anomalies. ${ }^{7,8}$ Contrast - enhanced computed tomography has a role in evaluating intraosseous lesions and the bony margins of extensive lesions that are under consideration for resection. Grey-scale ultrasound and Doppler analysis are useful in defining whether the lesion is solid or cystic and to establish the presence or absence of high flow vessels. Angiography, particularly digital subtraction angiography (DSA) has a specific but limited role in the diagnosis of vascular lesions; it should not be used as a first line investigation. It is however, useful for mapping out the blood supply of the lesion and in the assessment of the characteristics of flow of arteriovenous malformations. Angiography is usually reserved for therapeutic endovascular interventions. Direct intralesional injection of contrast medium may have a role in the analysis of venous malformations. ${ }^{8}$ The common nonsurgical methods ${ }^{9,10}$ of treating hemangiomas include injections of corticosteroids and sclerosants;selective ligation of peripheral vessels and embolization with steel coils,gelfoam,dura,silicone beads, alcohol and cyanoacrylate. ${ }^{11,12}$ High doses of corticosteroids remain the premier pharmacologic agent for control of aggressive hemangiomas and are known to be more effective in younger infants with proliferating hemangiomas than in older infants. ${ }^{9,13}$

Sclerosants are best adjuncts to subsequent surgery, but has the disadvantage of causing excessive scarring. Cryotherapy is an effective treatment for small superficial lesions and the efficacy of laser is unquestionable in portwine stain..$^{9,10}$ Surgical excision of small vascular growths is possible without undue risk of haemorrhage or of causing any cosmetic or functional deficiency; whereas total resection of large, localized deforming vascular lesions involves the possibility of massive haemorrhage during surgery and the need for major reconstructive procedures after resection.

\section{Conclusion}

Management of vascular malformations has always been a challenge, though with recent advances in imaging modalities and more treatment options at the disposal of clinicians, this scenario has become a lot easier. The complex and diverse presentation of these lesions highlights the importance of the needs for thorough investigation and a multidisciplinary approach in management of these lesions.

\section{Acknowledgements}

None.

\section{Conflict of interest}

The author declares no conflict of interest.

\section{References}

1. Mulliken JB, Young AE. Vascular Birthmarks: Hemangiomas and Malformation. Philadelphia, USA: WB Saunders; 1988. p. 228-245.

2. Mulliken JB, Glowacki J. Hemangiomas and vascular malformations in infants and children: a classification based on endothelial characteristics. Plast Reconstr Surg. 1982;69(3):412-422.

3. Kaban LB, Mulliken JB. Vascular anomalies of the maxillofacial region. J Oral Maxillofac Surg. 1986;44(3):203-213.

4. Zheng JW, Zhou Q, Yang XJ, et al. Treatment guideline for hemangiomas and vascular malformations of the head and neck. Head Neck. 2010;32(8):1088-1098.

5. Waner M, Suen JY. Hemangiomas and vascular malformations of the head and neck. New York, USA: John Wiley and Sons; 1999. p. 20-26.

6. Ethunandan M, Mellor TK. Haemangiomas and vascular malformations of the maxillofacial region-a review. Br J Oral Maxillofac Surg. 2006;44(4):263-272.

7. Burrows P, Laor T, Paltiel H. Diagnostic imaging in the evaluation of vascular birthmarks. Dermatol Clin. 1998;16(3):455-488.

8. Robertson RL, Robson CD, Barnes PD, et al. Head and neck vascular anomalies of childhood. Neuroimaging Clin N Am. 1999;9(1):115-132.

9. Meyer JS, Hoffer FA, Bames PD, et al. Biological classification of softtissue vascular anomalies: MR correlation. AJR. 1991;157(3):559-564.

10. Baurmash H, DeChiara S. A conservative approach to the management of orofacial vascular lesions in infants and children:Report of cases. $J$ Oral Maxillofac Surg. 1991;49(11):1222-1225.

11. Frame JW, Putnam G, Wake MJC, et al. Therapeutic arterial embolization of vascular lesions in the maxillofacial region. Br J Oral Maxillofac Surg. 1987;25(3):181-194.

12. HashimotoY, Matsuhiro K, Nagaki M, et al. Therapeutic embolization for vascular lesions of the head and neck: report of 2 cases. Int $J$ Oral Maxillofac Surg. 1989;18(1):47-49.

13. Alster TS, Wilson F. Treatment of port-wine stains with the flashlamppumped pulsed dye laser:extended clinical experience in children and adults. Ann Plast Surg. 1994;32(5):478-484. 